\title{
Electrocatalytic Study of Paracetamol at a Single-Walled Carbon Nanotube/Nickel Nanocomposite Modified Glassy Carbon Electrode
}

\author{
Koh Sing Ngai, ${ }^{1}$ Wee Tee Tan, ${ }^{1}$ Zulkarnain Zainal, ${ }^{1}$ \\ Ruzniza Mohd Zawawi, ${ }^{1}$ and Joon Ching Juan ${ }^{2}$ \\ ${ }^{1}$ Department of Chemistry, Faculty of Science, Universiti Putra Malaysia, 43400 UPM Serdang, Selangor, Malaysia \\ ${ }^{2}$ Nanotechnology \& Catalysis Research Centre (NANOCAT), University of Malaya, 50603 Kuala Lumpur, Malaysia
}

Correspondence should be addressed to Koh Sing Ngai; nkohsing@yahoo.com

Received 27 October 2014; Revised 16 January 2015; Accepted 19 January 2015

Academic Editor: Chi-Wai Chow

Copyright (c) 2015 Koh Sing Ngai et al. This is an open access article distributed under the Creative Commons Attribution License, which permits unrestricted use, distribution, and reproduction in any medium, provided the original work is properly cited.

A rapid, simple, and sensitive method for the electrochemical determination of paracetamol was developed. A single-walled carbon nanotube/nickel (SWCNT/Ni) nanocomposite was prepared and immobilized on a glassy carbon electrode (GCE) surface via mechanical attachment. This paper reports the voltammetry study on the effect of paracetamol concentration, scan rate, $\mathrm{pH}$, and temperature at a SWCNT/Ni-modified electrode in the determination of paracetamol. The characterization of the SWCNT/Ni/GCE was performed by cyclic voltammetry. Variable pressure scanning electron microscopy (VPSEM) and energy dispersive X-ray (EDX) spectrometer were used to examine the surface morphology and elemental profile of the modified electrode, respectively. Cyclic voltammetry showed significant enhancement in peak current for the determination of paracetamol at the SWCNT/Nimodified electrode. A linear calibration curve was obtained for the paracetamol concentration between 0.05 and $0.50 \mathrm{mM}$. The SWCNT/Ni/GCE displayed a sensitivity of $64 \mathrm{~mA} \mathrm{M}^{-1}$ and a detection limit of $1.17 \times 10^{-7} \mathrm{M}$ in paracetamol detection. The proposed electrode can be applied for the determination of paracetamol in real pharmaceutical samples with satisfactory performance. Results indicate that electrodes modified with SWCNT and nickel nanoparticles exhibit better electrocatalytic activity towards paracetamol.

\section{Introduction}

The demand for new sensor materials is increasing due to the growing electrochemical industry. Nanomaterials have received considerable attention recently due to their excellent physicochemical properties and potential applications in electrocatalysts, photocatalysts, supercapacitors, and field emission devices. Electrodes modified with nanomaterials exhibit excellent characteristics that are superior to conventional mediators, such as metal oxides [1], polymers [25], inorganic complexes [6], and DNA [7]. Research on modified electrodes with nanomaterials has been conducted with different types of nanoparticles $[8,9]$, carbon nanotubes (CNTs) [10-14], and composites of nanomaterials [15-24].

CNTs have unique properties, such as superior thermal and electrical conductivities, excellent physicochemical properties, and high surface area $[12,13]$. The single-walled carbon nanotube (SWCNT), a one-dimensional nanostructured material, is widely used in electrode modification due to its high surface to volume ratio. SWCNTs have the advantage over multiwalled carbon nanotubes (MWCNTs) due to their unique cylindrical single graphite sheet and excellent electron transfer activity. CNT modified electrodes have been evaluated and are considered to have good sensitivity and reproducibility $[12,13,25]$.

Mechanical attachment [21] is a simple and inexpensive method for the fabrication of chemically modified electrode (CME). Great attention has recently been centered on the CME via CNTs, through the determination of various substances such as metal ions $[8,26]$, antibiotics [27], biochemicals [28-31], chemicals [32], and drugs $[33,34]$. Nanoparticles exhibit good electrocatalytic activity with some electroactive substances including paracetamol. A hybrid of SWCNT and nanoparticles could be used as 
a promising electron transfer mediator. The configuration of SWCNT/nanoparticles nanocomposite attracts great interest due to its three-dimensional nanostructures with high surface areas.

Paracetamol (acetaminophen, 4-acetamidophenol, or Nacetyl-p-aminophenol) is a pharmaceutical product with antipyretic and analgesic properties. It is an effective drug used to relief headache, toothache, neckache, and various pains. Paracetamol is also widely prescribed for cold, flu, and fever. Chronic use or overdose of paracetamol leads to the accumulation of toxic metabolites in the liver, which may cause severe or fatal hepatotoxicity and nephrotoxicity, skin rashes, and pancreas inflammation. Quantitative determination of paracetamol is important in the quality assurance of pharmaceutical industry and vital for the healthcare industry. Therefore, the development of a simple, rapid, sensitive, and accurate analytical method for the determination of paracetamol is needed. The electrochemical determination of paracetamol using various modified electrodes constructed from CNTs has been reported [12, 14, 25, 35-38].

In this paper, a composite made of single-walled carbon nanotubes and nickel was selected as the mediator and used in the fabrication of GCEs. A sensitive electroanalytical methodology based on SWCNT and nickel-modified GCE for the determination of paracetamol was developed. Cyclic voltammetry for the characterization of the SWCNT/Nimodified electrode will be discussed.

\section{Materials and Methods}

2.1. Chemicals and Reagents. Single-walled carbon nanotubes (SWCNTs) with the purity of $90 \%$ and nickel (Ni) nanoparticles (99.9\%, 40-60 nm) were purchased from SkySpring Nanomaterials, Inc. Panadol (GlaxoSmithKline, GSK), a commercial product for paracetamol, was used for the recovery study. All the following chemicals were used without further purification: paracetamol (or $4^{\prime}$-hydroxyacetanilide, $\mathrm{C}_{8} \mathrm{H}_{9} \mathrm{NO}_{2}$ ) from Merck Schuchardt OHG, Germany, and potassium dihydrogen phosphate $\left(\mathrm{KH}_{2} \mathrm{PO}_{4}\right)$. Deionized water from Reverse Osmosis Water Purifier was used for all solution preparations.

2.2. Instrumentation. An electrochemical workstation CV50W Voltammetric Analyzer, Bioanalytical Systems, Inc. (BASi), connected to an external desktop computer, was used for all voltammetric measurements. Examination of the surface morphology of the nanocomposite was carried out using a variable pressure scanning electron microscope (LEO 1455 VPSEM) attached to an energy dispersive X-ray spectrometer (Oxford Inca EDX) with an acceleration voltage of $20 \mathrm{kV}$.

2.3. Preparation of Modified Electrode. Prior to use, the surface of the GCE was polished with $0.05 \mu \mathrm{m}$ alumina slurry and cleaned in an ultrasonic bath for 3 minutes. A SWCNT/Ni-modified electrode was prepared as follows: highly pure SWCNT nanopowder and nickel nanoparticles were mixed in a 1:2 ratio until a homogenous nanocomposite was obtained. The prepared SWCNT/Ni composite was deposited on the GCE surface ( $3 \mathrm{~mm}$ in diameter) via mechanical attachment [21]. Dissolved oxygen was removed from the electrolyte by bubbling pure nitrogen gas through the solution prior to electrochemical measurements.

\subsection{Electrochemical Characterization. An appropriate} amount of paracetamol standard solution was added to an electrolytic cell containing about $10 \mathrm{~mL}$ of $0.1 \mathrm{M}$ $\mathrm{KH}_{2} \mathrm{PO}_{4}$ electrolyte solution at $\mathrm{pH}$ 5.2. A three-electrode configuration was used, with the SWCNT/Ni-modified GCE employed as the working electrode. A silver/silver chloride (Ag/AgCl, $3 \mathrm{M} \mathrm{KCl})$ electrode and a platinum wire $(1 \mathrm{~mm}$ diameter) were used as reference electrode and auxiliary electrode, respectively. Unless otherwise indicated, all the electrochemical measurements were performed between -1.0 and $1.0 \mathrm{~V}$, at a scan rate of $100 \mathrm{mV} \mathrm{s}^{-1}$ and temperature of $25 \pm 2^{\circ} \mathrm{C}$.

\section{Results and Discussion}

3.1. Electrode Morphology. The SWCNT/Ni nanofilm that was deposited on the basal plane pyrolytic graphite electrode (BPPGE) was examined using VPSEM. The micrograph of the graphite electrode surface prior to electroanalysis is shown in Figure 1(a). It is apparent from the figure that the irregularly shaped SWCNT/Ni nanocomposite was distributed on the graphite surface in bundles with diameters in the range of 1 to $4 \mu \mathrm{m}$. Irregular arrays of microcrystals and surface porosity were obtained. The SWCNT/Ni-modified electrode was then immersed in $0.1 \mathrm{M} \mathrm{KH_{2 }} \mathrm{PO}_{4}$ solution containing $0.1 \mathrm{mM}$ paracetamol and subjected to cyclic voltammetry. The scanning electron micrographic image of the SWCNT/Ni nanocomposite after electroanalysis was recorded as in Figure 1(b). However, it was also observed that the nanocomposites increased in size from 1-4 to $4-10 \mu \mathrm{m}$. The strong attraction of paracetamol to the SWCNT/Ni nanofilm may be due to the electrostatic interaction between the nanomaterials and the electroactive species.

3.2. Enhancement Study. An experiment was performed to elucidate the electrochemical behavior of SWCNT/Ni/GCE towards the redox reaction of paracetamol. Figure 2 depicts the voltammograms of $0.1 \mathrm{mM}$ paracetamol in $0.1 \mathrm{M} \mathrm{KH}_{2} \mathrm{PO}_{4}$ at (a) bare GCE, (b) Ni-modified GCE, and (c) SWCNT/Nimodified GCE in $0.1 \mathrm{M} \mathrm{KH}_{2} \mathrm{PO}_{4}$ solution. A pair of stable and well-defined curves was observed with the bare and modified electrodes. The enhancement factor of 5 in anodic peak current infers that SWCNT/Ni-modified GCE is more sensitive than the other electrodes in the determination of paracetamol and that the SWCNT/Ni nanofilm has good electrocatalytic activity with paracetamol.

The suggestive scheme for the mediator behavior of nanofilm in the electrocatalytic oxidation of paracetamol is shown in Figure 3. The enhanced peak current could be attributed to the better electron conductivity of SWCNT/Ni/GCE. The SWCNT/Ni immobilized on the GCE electrode surface provides a high surface area, which increases the conductive surface, facilitating electron transfer $[12,25]$, and leads to higher sensitivity when compared to 




(a)

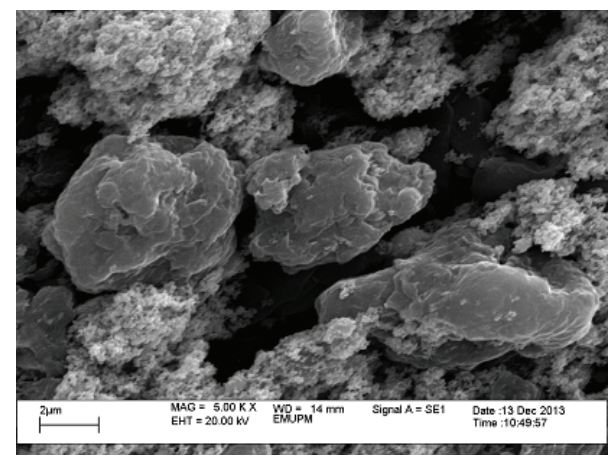

(b)

FIGURE 1: Variable pressure scanning electron microscopy (VPSEM) images of SWCNT/Ni composites on a basal plane pyrolytic graphite electrode (BPPGE, $5 \mathrm{~mm}$ diameter) surface (a) before and (b) after the electroanalysis.

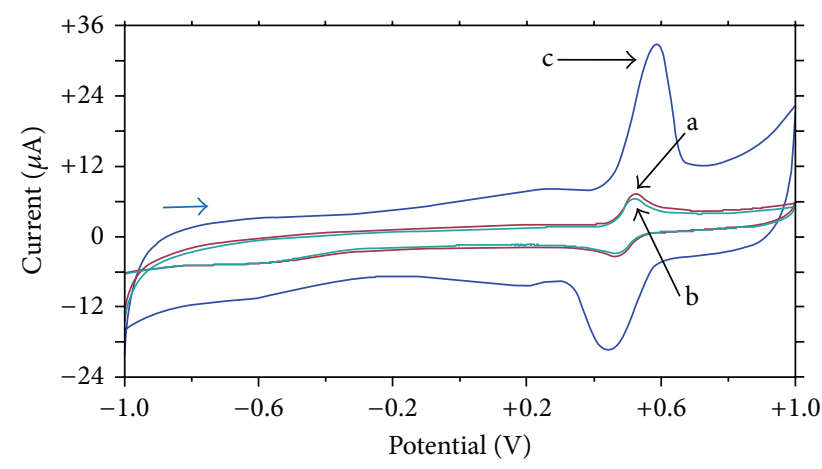

FIGURE 2: Cyclic voltammetry scanning of $0.1 \mathrm{mM}$ paracetamol in $0.1 \mathrm{M} \mathrm{KH}_{2} \mathrm{PO}_{4}$ at (a) bare GCE, (b) Ni-modified GCE, and (c) SWCNT/Ni-modified GCE versus Ag/AgCl. Scan rate: $100 \mathrm{mV} \mathrm{s}^{-1}$.

a bare GCE. It is clear that the SWCNT/Ni nanofilm can be used as a potential electron transfer mediator for the determination of paracetamol.

3.3. Effect of Scan Rate. The effect of varying scan rate is used to determine the type of mass transport process involved and to study electrode kinetics. Cyclic voltammograms of the electrocatalytic reaction of paracetamol at a SWCNT/Ni/GCE were obtained at increasing scan rates in the range of $2-1000 \mathrm{mV} \mathrm{s}^{-1}$. The increase in the scan rate induced an increase in the anodic peak current, which resulted in the shifting of the anodic peak current in a more positive potential direction. As shown in the plot of log anodic peak current against log scan rate (Figure 4), the peak current response increased linearly with the scan rate. The linear regression equation was $y=0.685 x+0.319$ with a correction coefficient of 0.999 . Based on the equation obtained, a slope of 0.69 reveals that the mass transport of electroactive species towards electrode surface is controlled by both diffusion and adsorption processes.

3.4. Effect of Potential Cycling. The stability of the SWCNT/ $\mathrm{Ni}$-modified electrode was evaluated by cyclic voltammetry. The modified electrode was subjected to 5 continuous

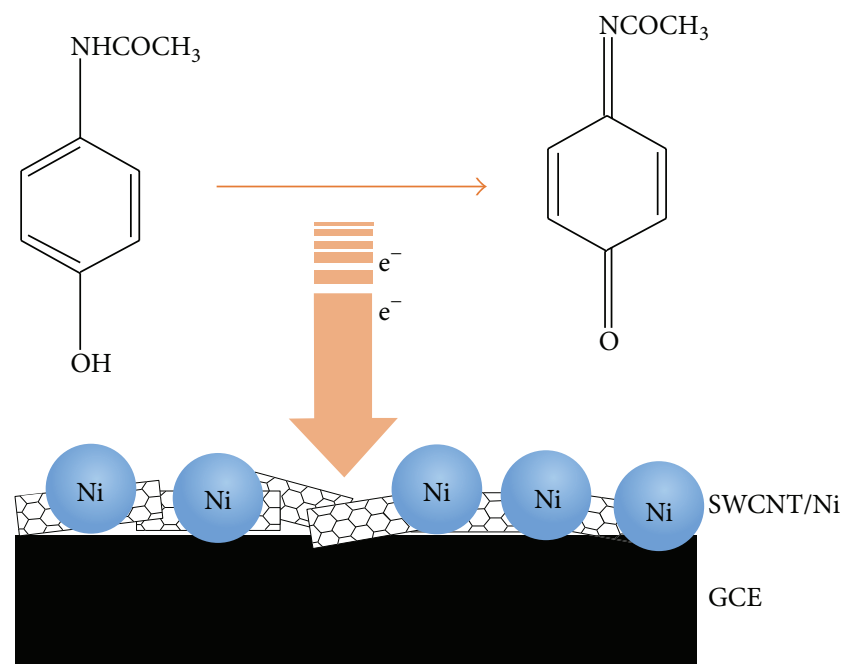

FIGURE 3: The suggestive scheme for the mediator behavior of SWCNT/Ni nanoparticles in electrocatalytic reaction of paracetamol.

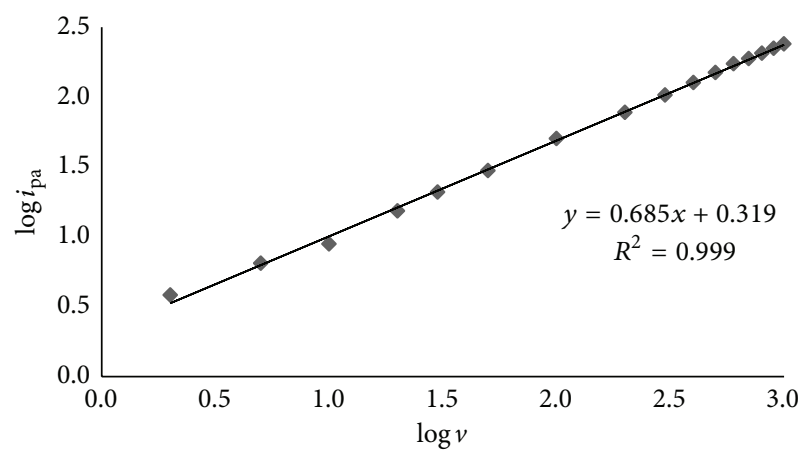

Figure 4: Plot of $\log i_{\text {pa }}$ versus $\log v$.

potential cycles to study the stability of the electrocatalytic reaction of paracetamol. A significant decay was observed in the peak current during the first cycle (Figure 5). This suggests that the nanocomposite was weakly bonded to the electrode surface by mechanical attachment technique. 


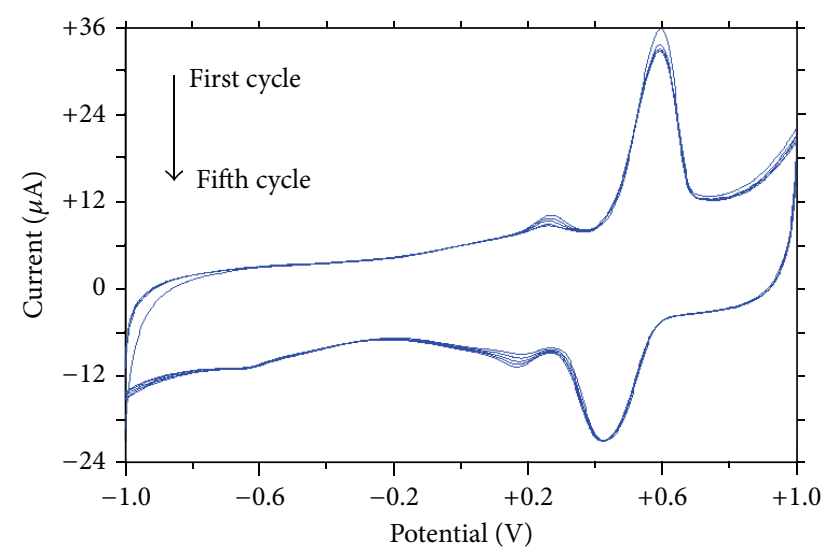

FIGURE 5: Multiple cycle voltammograms for $0.1 \mathrm{mM}$ paracetamol in $0.1 \mathrm{M} \mathrm{KH} \mathrm{KO}_{4}$ at a SWCNT/Ni-modified electrode. Scan rate: $100 \mathrm{mV} \mathrm{s}^{-1}$.

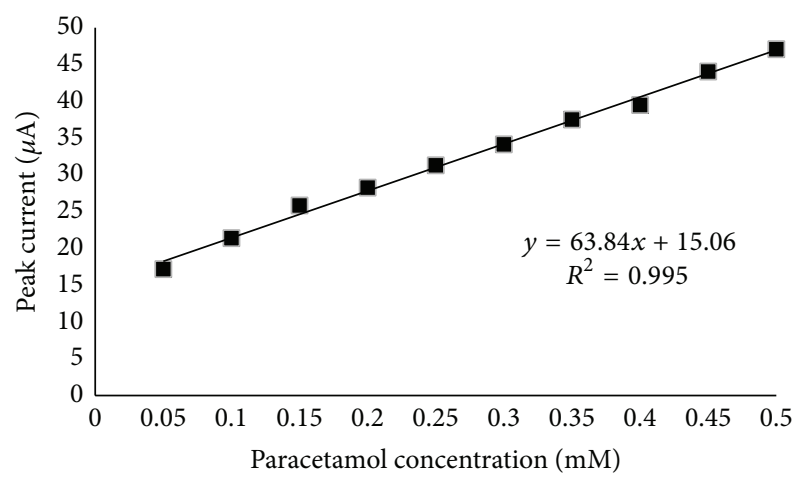

FIGURE 6: Standard calibration plot of paracetamol in $0.1 \mathrm{M} \mathrm{KH}_{2} \mathrm{PO}_{4}$ using a SWCNT/Ni-modified electrode versus $\mathrm{Ag} / \mathrm{AgCl}$.

Stability was observed in the peak currents from the second cycle onwards. Even after the fifth cycle, the anodic peak current for the oxidation of paracetamol remained high. The stability of the modified electrode could be attributed to the presence of the nanofilm, which forms a networklike nanostructure that restricts the loss of the SWCNT/Ni nanocomposite. The SWCNT/Ni/GCE was relatively stable while in $0.1 \mathrm{M} \mathrm{KH}_{2} \mathrm{PO}_{4}$.

3.5. Effect of Paracetamol Concentration. The effect of varying paracetamol concentration in $0.1 \mathrm{M} \mathrm{KH}_{2} \mathrm{PO}_{4}$ electrolyte solution was explored at the SWCNT/Ni/GCE. A series of welldefined peaks was obtained from the voltammetric responses to the additions of paracetamol over the range of $0.05-$ $0.50 \mathrm{mM}$. A linear relationship was developed between the anodic peak current $\left(i_{\mathrm{pa}}\right)$ and the concentration of paracetamol (Figure 6). As described by the equation $y=63.84 x+$ 15.06 , a good sensitivity response towards the oxidation of paracetamol was found to be $64 \mathrm{mM} \mathrm{A}^{-1}$. Using the plot, an excellent correlation of $R^{2}=0.995$ was determined and a low detection limit of $1.17 \times 10^{-7} \mathrm{M}$ was obtained. The electrochemical behavior of the SWCNT/Ni-modified GCE for the determination of paracetamol is comparable to some of the previously reported electrodes $[12,39]$.

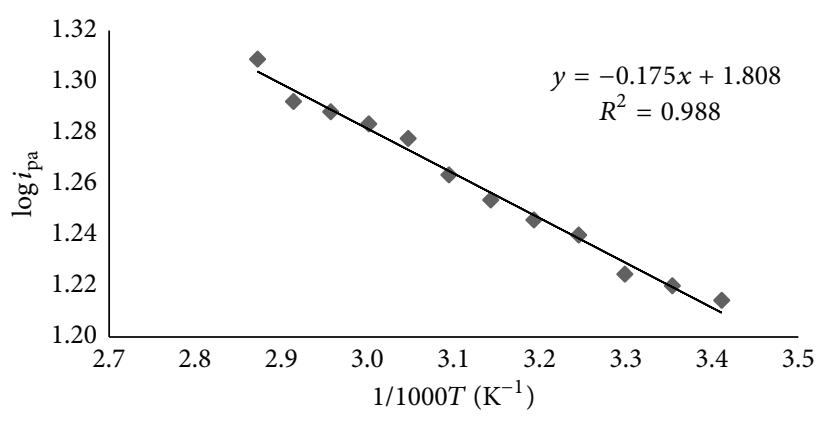

FIGURE 7: Plot of anodic peak current versus reciprocal of temperature for the electrolysis of $0.1 \mathrm{mM}$ paracetamol at a SWCNT/Nimodified electrode. Scan rate: $100 \mathrm{mV} \mathrm{s}^{-1}$.

3.6. Effect of Temperature. The effect of temperature on the determination of paracetamol at the SWCNT/Ni-modified electrode was examined by cyclic voltammetry. The peak current increased gradually when temperature was increased in the range of $20-75^{\circ} \mathrm{C}$. A plot of log anodic peak current against reciprocal of temperature was obtained with a slope of 0.175 (Figure 7). The plot was fairly linear and was in agreement with the thermodynamic expectation of Arrhenius equations [39].

The relationships between conductivity, diffusibility, and temperature are described by the following Arrhenius equation:

$$
\begin{aligned}
& \sigma=\sigma^{o} \operatorname{Exp}\left(-\frac{E_{a}}{R T}\right), \\
& D=D^{o} \operatorname{Exp}\left(-\frac{E_{a}}{R T}\right),
\end{aligned}
$$

where $\sigma$ is conductivity, $\sigma^{o}$ is standard conductivity, $D$ is diffusibility, $D^{\circ}$ is standard diffusibility, $E_{a}$ is activation energy, $R$ is specific gas constant $\left(8.314 \mathrm{~J} \mathrm{~K}^{-1} \mathrm{~mol}^{-1}\right)$, and $T$ is temperature $(\mathrm{K}) . \sigma / D$ are conductivity/diffusibility and $\sigma^{o} / D^{o}$ are standard conductivity/initial diffusibility.

Based on the Arrhenius plot, the activation energy of $1.45 \mathrm{~kJ} \mathrm{~mol}^{-1}$ was determined. The elevation of temperature was accompanied with an increase in peak current and shifting of peak potential towards a lower potential. The diffusion resistance of the electrode surface decreased with increasing temperature. This contributed to improved electron transfer rate at the electrode/electrolyte interface, which led to the higher anodic peak current. Therefore, the electrocatalytic reaction of paracetamol at the SWCNT/Ni/GCE is significantly temperature dependent.

3.7. Effect of $p H$. In most cases, the $\mathrm{pH}$ of the electrolyte solution is an important factor that influences the electrochemical reaction at an electrode surface. The study of varying solution $\mathrm{pH}$ is to determine the optimum $\mathrm{pH}$ for an electrocatalytic reaction and the number of protons involved in the reaction. The effect of $\mathrm{pH}$ was investigated in the range of 3-12 at the SWCNT/Ni/GCE. Figure 8 illustrates the change of anodic peak current for $0.1 \mathrm{mM}$ paracetamol by varying the $\mathrm{pH}$ of $0.1 \mathrm{M} \mathrm{KH}_{2} \mathrm{PO}_{4}$ supporting electrolyte. As can be seen from 


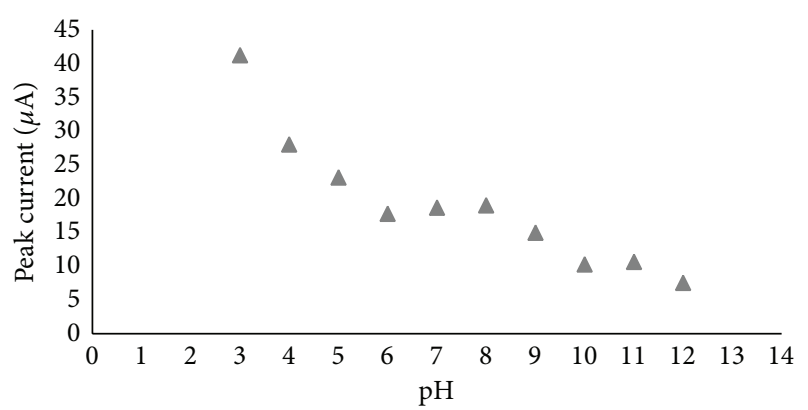

FIGURE 8: Effect of solution $\mathrm{pH}$ on the electrocatalytic activity of a SWCNT/Ni-modified GCE. Scan rate: $100 \mathrm{mV} \mathrm{s}^{-1}$. pH: 3-12.

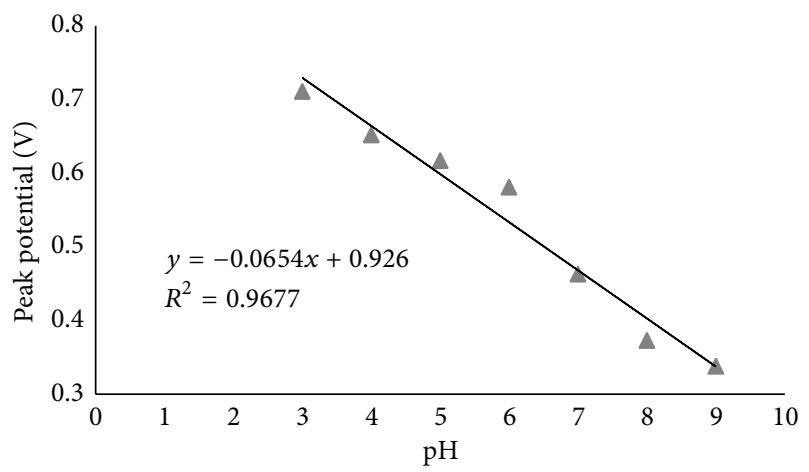

Figure 9: A plot of anodic peak potential for the electrochemical reaction of $0.1 \mathrm{mM}$ paracetamol in various $\mathrm{pH}$ of $0.1 \mathrm{M} \mathrm{KH}_{2} \mathrm{PO}_{4}$ electrolyte solution at a SWCNT/Ni/GCE. Scan rate: $100 \mathrm{mV} \mathrm{s}^{-1} \cdot \mathrm{pH}$ : 3-9.

the plot, the peak current of paracetamol increased when $\mathrm{pH}$ was reduced from 5 to 3 . The maximum current response was observed at $\mathrm{pH} 3$. The anodic peak current increased slightly by increasing the $\mathrm{pH}$ from 6 to 8 . Higher than $\mathrm{pH} 9$, the peak current response decreased significantly, which was probably due to the deprotonation in the oxidation process that favors a higher $\mathrm{pH}$. Acidic electrolytic solution promotes electron transfer and hence the oxidation of paracetamol. When $\mathrm{pH}$ increases, deprotonation occurs. At higher $\mathrm{pH}$, the anodic peak current diminishes. The results indicate that the redox response of paracetamol is $\mathrm{pH}$ dependent at the SWCNT/Nimodified GCE.

It was also found that the peak potential for paracetamol varies with $\mathrm{pH}$, reducing with the increase of $\mathrm{pH}$ (Figure 9). This suggests that protons are involved in the electrode process. In a Nernstian reaction, $E_{\mathrm{pa}}$ is described as a function of solution $\mathrm{pH}$ where the slope is equal to $0.0592(\mathrm{~m} / \mathrm{n}) \mathrm{V}$ per unit $\mathrm{pH}$. $m$ and $n$ are the number of protons and electrons which are taking part in the electrode reaction, respectively. Based on the plot, the relationship between the peak potentials and $\mathrm{pH}$ is linear and is described as $E_{\mathrm{pa}}=$ $0.926-0.065 \mathrm{pH}$, with an $R^{2}$ of 0.968 . The results suggest that, in the oxidation of one unit of paracetamol molecule, two electrons and two protons are produced.
TABLE 1: Repeatability study for the determination of paracetamol at SWCNT/Ni-modified electrodes.

\begin{tabular}{lc}
\hline Repetition & Peak current \\
\hline & $\mu \mathrm{A}$ \\
1 & 26.15 \\
3 & 29.96 \\
4 & 28.43 \\
5 & 27.73 \\
Mean & 29.85 \\
RSD (\%) & 28.42 \\
\hline
\end{tabular}

TABLE 2: Recovery study for the electrochemical process of commercial sample (Panadol). Five replicates of $1.0 \mathrm{mM}$ paracetamol determination at SWCNT/Ni-modified electrodes.

\begin{tabular}{lcccc}
\hline $\begin{array}{l}\text { Real life } \\
\text { sample }\end{array}$ & $\begin{array}{c}\text { Recovered } \\
\text { concentration } \\
(\mathrm{mM})\end{array}$ & $\begin{array}{c}\text { Recovery } \\
\text { rate } \\
(\%)\end{array}$ & $\begin{array}{c}\text { Mean } \\
\text { recovery } \\
(\%)\end{array}$ & $\begin{array}{c}\text { RSD } \\
(\%)\end{array}$ \\
\hline 1 & 1.034 & 103.4 & & \\
2 & 0.973 & 97.3 & & \\
3 & 0.956 & 95.6 & 96.9 & 1.9 \\
4 & 0.945 & 94.5 & & \\
5 & 0.937 & 93.7 & & \\
\hline
\end{tabular}

3.8. Repeatability. To evaluate the repeatability of the proposed method, the SWCNT/Ni-modified electrode was subjected to a reproducibility study in which five measurements were obtained for every freshly prepared modified electrode. Table 1 shows the anodic peak current at the SWCNT/Ni/GCE for the determination of paracetamol in $0.1 \mathrm{M} \mathrm{KH}_{2} \mathrm{PO}_{4}$ electrolyte solution. The determination of paracetamol was performed at a newly constructed modified electrode on different days. The relative standard deviation (RSD) of the five measurements was calculated to be $5.6 \%$, which demonstrates the repeatability of the method. The data indicate that the SWCNT/Ni/GCE adopted in the determination of paracetamol and the fabrication technique will produce highly reproducible results. Similar results have been previously reported by using graphene-modified GCEs [40].

3.9. Recovery. In order to evaluate the practical utility and validity of the SWCNT/Ni-modified electrode, the modified electrode was examined with commercial paracetamol pills using cyclic voltammetry. Table 2 shows the results obtained from the SWCNT/Ni-modified electrode for $1.0 \mathrm{mM}$ paracetamol in Panadol pills (GSK). Five replicate measurements for the determination of paracetamol with a fresh electrode surface at every measurement produced a mean recovery of $96.9 \pm 1.9 \%$. From the results obtained, it can be seen that the SWCNT/Ni/GCE demonstrated good electrocatalytic activity. Good recovery indicates the suitability and reliability of the proposed method. Therefore, the SWCNT/Ni-modified electrode is reliable and thus is recommended for routine analyses. 
TABLE 3: The elemental profile of the SWCNT/Ni nanofilm deposited on the BPPGE surface (a) before and (b) after the electroanalysis in $0.1 \mathrm{M} \mathrm{KH}_{2} \mathrm{PO}_{4}$ electrolyte containing $0.1 \mathrm{mM}$ paracetamol. Scan rate: $100 \mathrm{mV} \mathrm{s}^{-1}$.

(a)

\begin{tabular}{lcccc}
\hline Spectrum & In stats. & $\mathrm{C}$ & $\mathrm{Ni}$ & Total \\
\hline Spectrum 1 & Yes & 67.71 & 32.29 & 100.00 \\
Spectrum 2 & Yes & 94.94 & 5.06 & 100.00 \\
Spectrum 3 & Yes & 93.26 & 6.74 & 100.00 \\
Spectrum 4 & Yes & 94.93 & 5.07 & 100.00 \\
\hline Mean & & 87.71 & 12.29 & 100.00 \\
Std. deviation & & 13.36 & 13.36 & \\
Max. & & 94.94 & 32.29 & \\
Min. & & 67.71 & 5.06 & \\
\hline
\end{tabular}

(b)

\begin{tabular}{lccccccc}
\hline Spectrum & In stats. & $\mathrm{C}$ & $\mathrm{O}$ & $\mathrm{P}$ & $\mathrm{K}$ & $\mathrm{Ni}$ & Total \\
\hline Spectrum 1 & Yes & 20.88 & 13.54 & & 0.70 & 64.88 & 100.00 \\
Spectrum 2 & Yes & 68.12 & 21.52 & 1.50 & 1.92 & 6.95 & 100.00 \\
Spectrum 3 & Yes & 78.55 & 5.08 & & 0.32 & 16.06 & 100.00 \\
Spectrum 4 & Yes & 68.89 & 20.00 & 1.57 & 2.11 & 7.43 & 100.00 \\
\hline Max. & & 78.55 & 21.52 & 1.57 & 2.11 & 64.88 & \\
Min. & & 20.88 & 5.08 & 1.50 & 0.32 & 6.95 & \\
\hline
\end{tabular}

3.10. Elemental Study. The attachment of SWCNT/Ni nanocomposite to the BPPGE surface and the elemental compositions of the nanofilm can be confirmed by using EDX. Table 3 presents the EDX data of the SWCNT/Ni nanofilm embedded on the BPPGE surface before and after the electrochemical cycles. As can be seen in the table, the EDX profiles show the presence of carbon and nickel prior to the electroanalysis. After the electroanalysis, the potassium, oxygen, and phosphorus spectra were found, which infer that the electrolyte component was incorporated into the nanostructure during the redox. The results suggest that the nanofilm underwent elemental modification.

\section{Conclusions}

A simple three-electrode system was employed for paracetamol determination. GCEs mechanically attached with SWCNT/Ni nanocomposite were prepared and used in the determination of paracetamol in $0.1 \mathrm{M} \mathrm{KH}_{2} \mathrm{PO}_{4}$ supporting electrolyte. The characterization studies indicate that the anodic peak current is affected by scan rate, paracetamol concentration, $\mathrm{pH}$, and temperature. The GCE modified with SWCNT/Ni nanocomposite provided good current response in low $\mathrm{pH}$. The modified electrode holds a promising prospect for the determination of paracetamol, with good repeatability and recovery. The SWCNT/Ni-modified GCE exhibited relatively stable and sensitive electrochemical behavior. Electrode preparation is quick and simple. Only small amounts of nanomaterials were used, minimizing wastage. Therefore, a chemically modified electrode fabricated with SWCNT/Ni nanocomposite via mechanical attachment technique can be used for the determination of paracetamol when coupled with cyclic voltammetric analysis.

\section{Conflict of Interests}

The authors declare that there is no conflict of interests regarding the publication of this paper.

\section{Acknowledgment}

The authors acknowledge the support for this study from the Department of Chemistry, Faculty of Science, Universiti Putra Malaysia.

\section{References}

[1] P. Shakkthivel and S.-M. Chen, "Simultaneous determination of ascorbic acid and dopamine in the presence of uric acid on ruthenium oxide modified electrode," Biosensors and Bioelectronics, vol. 22, no. 8, pp. 1680-1687, 2007.

[2] Y. Li and X. Lin, "Simultaneous electroanalysis of dopamine, ascorbic acid and uric acid by poly (vinyl alcohol) covalently modified glassy carbon electrode," Sensors and Actuators, B: Chemical, vol. 115, no. 1, pp. 134-139, 2006.

[3] P. Kalimuthu and S. A. John, "Electropolymerized film of functionalized thiadiazole on glassy carbon electrode for the simultaneous determination of ascorbic acid, dopamine and uric acid," Bioelectrochemistry, vol. 77, no. 1, pp. 13-18, 2009.

[4] A.-L. Liu, S.-B. Zhang, W. Chen, X.-H. Lin, and X.-H. Xia, "Simultaneous voltammetric determination of norepinephrine, ascorbic acid and uric acid on polycalconcarboxylic acid modified glassy carbon electrode," Biosensors and Bioelectronics, vol. 23, no. 10, pp. 1488-1495, 2008.

[5] M. M. Radhi, W. T. Tan, M. Z. B. A. Rahman, and A. B. Kassim, "Electrochemical characterization of the redox couple of $\left[\mathrm{Fe}(\mathrm{CN})_{6}\right]^{3-} /\left[\mathrm{Fe}(\mathrm{CN})_{6}\right]^{4-}$ mediated by a grafted polymer modified glassy carbon electrode," Journal of Chemical Engineering of Japan, vol. 43, no. 11, pp. 927-931, 2010.

[6] M. Wang, X. Xu, and J. Gao, "Voltammetric studies of a novel bicopper complex modified glassy carbon electrode for the simultaneous determination of dopamine and ascorbic acid," Journal of Applied Electrochemistry, vol. 37, no. 6, pp. 705-710, 2007.

[7] X. Li, Y. Chen, and X. Huang, "Electrochemical behavior of neomycin at DNA-modified gold electrodes," Journal of Inorganic Biochemistry, vol. 101, pp. 918-924, 2007.

[8] A. Salimi, H. Mamkhezri, R. Hallaj, and S. Soltanian, "Electrochemical detection of trace amount of arsenic(III) at glassy carbon electrode modified with cobalt oxide nanoparticles," Sensors and Actuators B: Chemical, vol. 129, no. 1, pp. 246-254, 2008.

[9] C. Shao, N. Lu, and Z. Deng, "DNA-assisted electroless deposition of highly dispersed palladium nanoparticles on glassy carbon surface: preparation and electrocatalytic properties," Journal of Electroanalytical Chemistry, vol. 629, no. 1-2, pp. 1522, 2009.

[10] A. Salimi, R. Hallaj, and G.-R. Khayatian, "Amperometric detection of morphine at preheated glassy carbon electrode modified with multiwall carbon nanotubes," Electroanalysis, vol. 17, no. 10, pp. 873-879, 2005. 
[11] Y.-Q. Dai and K.-K. Shiu, "Glucose biosensor based on multiwalled carbon nanotube modified glassy carbon electrode," Electroanalysis, vol. 16, no. 20, pp. 1697-1703, 2004.

[12] R. N. Goyal, V. K. Gupta, and S. Chatterjee, "Voltammetric biosensors for the determination of paracetamol at carbon nanotube modified pyrolytic graphite electrode," Sensors and Actuators B: Chemical, vol. 149, no. 1, pp. 252-258, 2010.

[13] B. Habibi, M. Jahanbakhshi, and M. H. Pournaghi-Azar, "Differential pulse voltammetric simultaneous determination of acetaminophen and ascorbic acid using single-walled carbon nanotube-modified carbon-ceramic electrode," Analytical Biochemistry, vol. 411, no. 2, pp. 167-175, 2011.

[14] R. T. Kachoosangi, G. G. Wildgoose, and R. G. Compton, "Sensitive adsorptive stripping voltammetric determination of paracetamol at multiwalled carbon nanotube modified basal plane pyrolytic graphite electrode," Analytica Chimica Acta, vol. 618, no. 1, pp. 54-60, 2008.

[15] S. Shahrokhian, M. Ghalkhani, M. Adeli, and M. K. Amini, "Multi-walled carbon nanotubes with immobilised cobalt nanoparticle for modification of glassy carbon electrode: application to sensitive voltammetric determination of thioridazine," Biosensors and Bioelectronics, vol. 24, no. 11, pp. 3235-3241, 2009.

[16] L. Qian, Q. Gao, Y. Song, Z. Li, and X. Yang, "Layer-by-layer assembled multilayer films of redox polymers for electrocatalytic oxidation of ascorbic acid," Sensors and Actuators B: Chemical, vol. 107, no. 1, pp. 303-310, 2005.

[17] S. Yang, L. Qu, G. Li, R. Yang, and C. Liu, "Gold nanoparticles/ ethylenediamine/carbon nanotube modified glassy carbon electrode as the voltammetric sensor for selective determination of rutin in the presence of ascorbic acid," Journal of Electroanalytical Chemistry, vol. 645, no. 2, pp. 115-122, 2010.

[18] M. Motahary, S. M. Ghoreishi, M. Behpour, and M. Golestaneh, "Electrochemical determination of ascorbic acid at the surface of a graphite electrode modified with multi-walled carbon: nanotubes/tetradecyltrimethylammonium bromide," Journal of Applied Electrochemistry, vol. 40, no. 4, pp. 841-847, 2010.

[19] X. Lin and Y. Li, "A sensitive determination of estrogens with a Pt nano-clusters/multi-walled carbon nanotubes modified glassy carbon electrode," Biosensors and Bioelectronics, vol. 22, pp. 253-259, 2006.

[20] J. Chen, W.-D. Zhang, and J.-S. Ye, "Nonenzymatic electrochemical glucose sensor based on $\mathrm{MnO}_{2}$ /MWNTs nanocomposite," Electrochemistry Communications, vol. 10, no. 9, pp. 1268-1271, 2008.

[21] M. Zidan, W. Tan, Z. Zainal, A. H. Abdullah, and J. K. Goh, "Electrocatalytic oxidation of ascorbic acid mediated by lithium doped microparticles $\mathrm{Bi}_{2} \mathrm{O}_{3}$ /MWCNT modified glassy carbon electrode," International Journal of Electrochemical Science, vol. 5, no. 4, pp. 501-508, 2010.

[22] H. Liu, G. Wang, D. Chen, W. Zhang, C. Li, and B. Fang, "Fabrication of polythionine/NPAu/MWNTs modified electrode for simultaneous determination of adenine and guanine in DNA," Sensors and Actuators B: Chemical, vol. 128, no. 2, pp. 414-421, 2008.

[23] S. Jo, H. Jeong, S. R. Bae, and S. Jeon, "Modified platinum electrode with phytic acid and single-walled carbon nanotube: application to the selective determination of dopamine in the presence of ascorbic and uric acids," Microchemical Journal, vol. 88, no. 1, pp. 1-6, 2008.

[24] M. Çubukçu, S. Timur, and Ü. Anik, "Examination of performance of glassy carbon paste electrode modified with gold nanoparticle and xanthine oxidase for xanthine and hypoxanthine detection," Talanta, vol. 74, no. 3, pp. 434-439, 2007.

[25] Q. Wan, X. Wang, F. Yu, X. Wang, and N. Yang, "Poly(taurine)/ MWNT-modified glassy carbon electrodes for the detection of acetaminophen," Journal of Applied Electrochemistry, vol. 39, no. 6, pp. 785-790, 2009.

[26] M. M. Radhi, W. T. Tan, M. Z. B. A. Rahman, and A. B. Kassim, "Voltammetric detection of $\mathrm{Mn}(\mathrm{II})$ in blood sample at $\mathrm{C}_{60}$ and MWCNT modified glassy carbon electrodes," The American Journal of Applied Sciences, vol. 7, no. 3, pp. 439-445, 2010.

[27] F. Xiao, F. Zhao, J. Li, R. Yan, J. Yu, and B. Zeng, "Sensitive voltammetric determination of chloramphenicol by using single-wall carbon nanotube-gold nanoparticle-ionic liquid composite film modified glassy carbon electrodes," Analytica Chimica Acta, vol. 596, no. 1, pp. 79-85, 2007.

[28] X. Wang, N. Yang, and Q. Wan, "Cyclic voltammetric response of nicotinic acid and nicotinamide on a polycrystalline gold electrode," Electrochimica Acta, vol. 52, no. 1, pp. 361-368, 2006.

[29] R. Zhang, X. Wang, and C. Chen, "Electrochemical biosensing platform using carbon nanotube activated glassy carbon electrode," Electroanalysis, vol. 19, no. 15, pp. 1623-1627, 2007.

[30] S. Zhu, H. Li, W. Niu, and G. Xu, "Simultaneous electrochemical determination of uric acid, dopamine, and ascorbic acid at single-walled carbon nanohorn modified glassy carbon electrode," Biosensors and Bioelectronics, vol. 25, no. 2, pp. 940-943, 2009.

[31] X.-H. Pham, M.-P. N. Bui, C. A. Li et al., "Electrochemical characterization of a single-walled carbon nanotube electrode for detection of glucose," Analytica Chimica Acta, vol. 671, no. 1-2, pp. 36-40, 2010.

[32] S. Chandra, K. S. Lokesh, A. Nicolai, and H. Lang, "Dendrimerrhodium nanoparticle modified glassy carbon electrode for amperometric detection of hydrogen peroxide," Analytica Chimica Acta, vol. 632, no. 1, pp. 63-68, 2009.

[33] B. Habibi, M. Abazari, and M. H. Pournaghi-Azar, "Simultaneous determination of codeine and caffeine using single-walled carbon nanotubes modified carbon-ceramic electrode," Colloids and Surfaces B: Biointerfaces, vol. 114, pp. 89-95, 2014.

[34] B. Habibi, M. Abazari, and M. H. Pournaghi-Azar, "A carbon nanotube modified electrode for determination of caffeine by differential pulse voltammetry," Chinese Journal of Catalysis, vol. 33, no. 11-12, pp. 1783-1790, 2012.

[35] T.-L. Lu and Y.-C. Tsai, "Sensitive electrochemical determination of acetaminophen in pharmaceutical formulations at multiwalled carbon nanotube-alumina-coated silica nanocomposite modified electrode," Sensors and Actuators, B: Chemical, vol. 153, no. 2, pp. 439-444, 2011.

[36] B. Habibi, M. Jahanbakhshi, and M. H. Pournaghi-Azar, "Simultaneous determination of acetaminophen and dopamine using SWCNT modified carbon-ceramic electrode by differential pulse voltammetry," Electrochimica Acta, vol. 56, no. 7, pp. 28882894, 2011.

[37] B. Habibi, M. Jahanbakhshi, and M. H. Pournaghiazar, "Electrochemical oxidation and nanomolar detection of acetaminophen at a carbon-ceramic electrode modified by carbon nanotubes: a comparison between multi walled and single walled carbon nanotubes," Microchimica Acta, vol. 172, no. 1, pp. 147-154, 2011.

[38] B. Habibi, M. Jahanbakhshi, and M. Abazari, "A modified single-walled carbon nanotubes/carbon-ceramic electrode for simultaneous voltammetric determination of paracetamol and caffeine," Journal of the Iranian Chemical Society, vol. 11, no. 2, pp. 511-521, 2014. 
[39] M. Zidan, T. W. Tee, A. H. Abdullah, Z. Zainal, and G. J. Kheng, "Electrochemical oxidation of paracetamol mediated by nanoparticles bismuth oxide modified glassy carbon electrode," International Journal of Electrochemical Science, vol. 6, no. 2, pp. 279-288, 2011.

[40] X. Kang, J. Wang, H. Wu, J. Liu, I. A. Aksay, and Y. Lin, "A graphene-based electrochemical sensor for sensitive detection of paracetamol," Talanta, vol. 81, no. 3, pp. 754-759, 2010. 

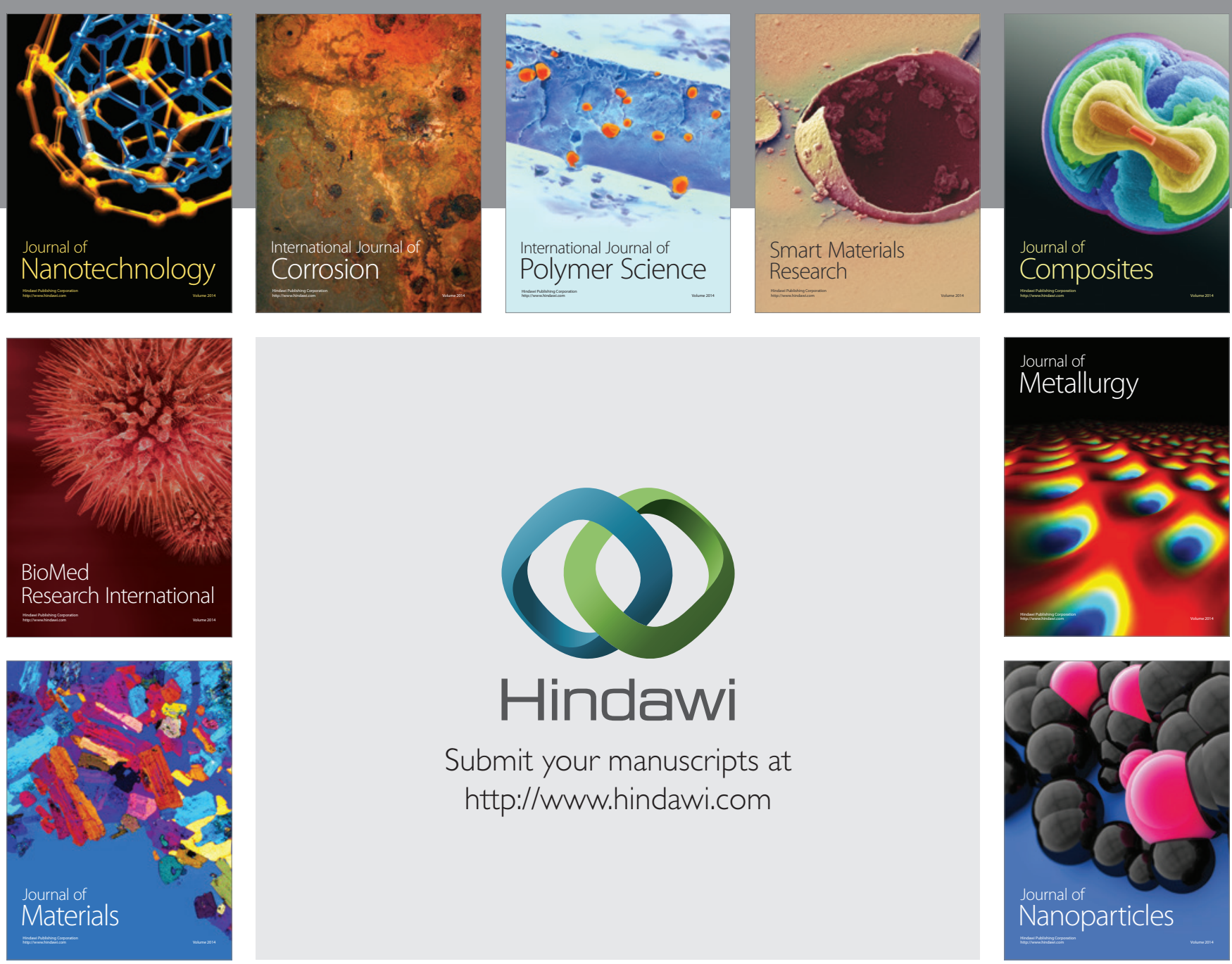

Submit your manuscripts at http://www.hindawi.com
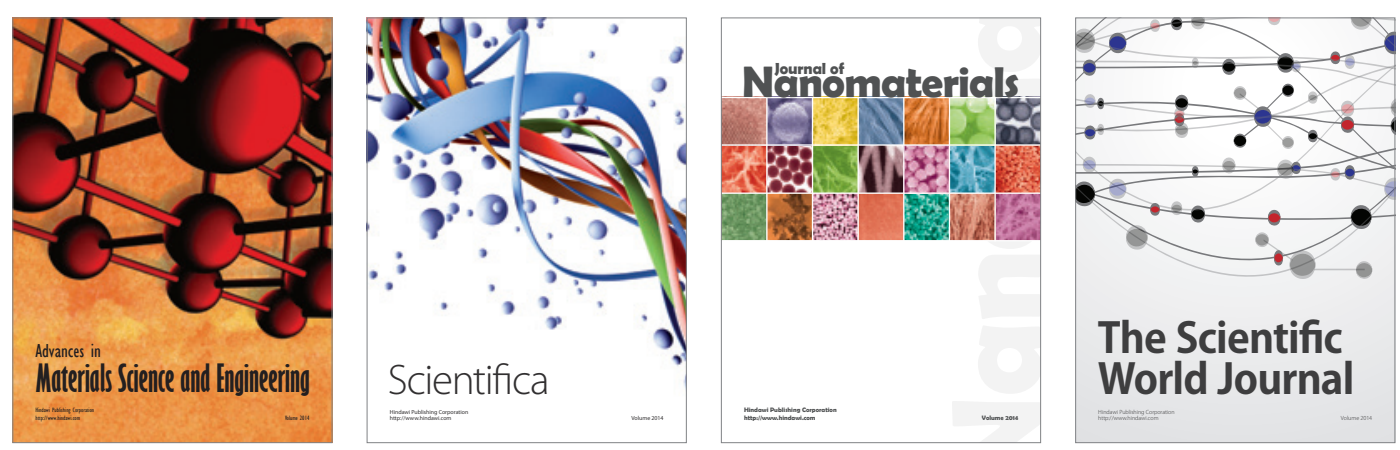

\section{The Scientific World Journal}
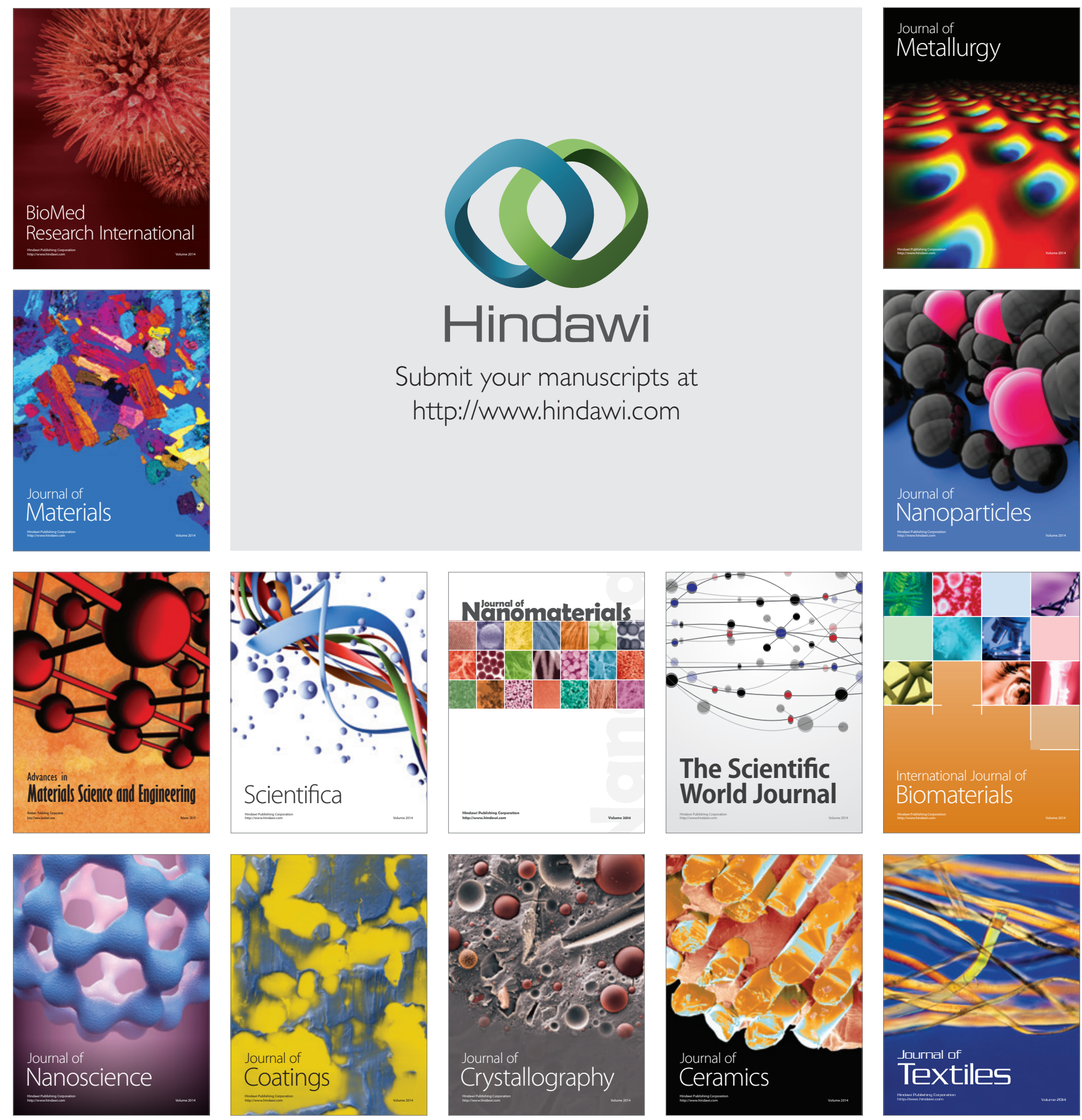